\title{
Managing quality of cost information in clinical costing: Evidence across seven countries
}

\begin{tabular}{|r|l|}
\hline Journal: & Journal of Public Budgeting, Accounting \& Financial Management \\
\hline Manuscript ID & JPBAFM-09-2020-0155.R2 \\
\hline Manuscript Type: & Research Paper \\
\hline Keywords: & $\begin{array}{l}\text { DRG based payment systems, Healthcare, Tariff Payment systems, } \\
\text { Materiality and Quality Score (MAQS), Quality of Cost Information }\end{array}$ \\
\hline \multicolumn{2}{|l}{} \\
\hline
\end{tabular}




\section{Introduction}

Understanding the drivers of quality of healthcare costing is essential for decision-making at all levels. At the provider level, cost information is used to inform local management decisions. It feeds into Diagnosis Related Group (DRG) based payment systems (Tan et al., 2014, 2011) at the regional or national level. Furthermore, cost information forms the basis of economic evaluations

10 at all levels, aiming to make healthcare services more efficient (Chapman, Kern, Laguecir and Quentin, 2016). Internationally, comparable cost information is a prerequisite for efficiency assessments and benchmarking (Linna et al., 2010; Busse, Schreyögg and Smith, 2008; and Schreyögg et al, 2008). However, recent research has pointed out that the quality of healthcare cost information is often limited (Hrifach et al., 2018; Chapman, Kern, Laguecir and Quentin, 2016;

15 Mercier and Naro, 2014; and Chapman and Kern, 2010). In this article we report on a study of approaches to clinical costing across seven countries to analyze relationships between different dimensions of quality of cost information with divergent regulatory purposes.

The accounting and health policy literature has identified three main dimensions of cost information quality. Firstly, the costing accuracy, regarding how cost information reflects actual consumption (Mercier and Naro, 2014). In practice, costing data are always inaccurate to some degree (Labro and Vanhoucke, 2007), as it would be too costly to assign all costs strictly accurately to cost objects. In other words, perfect costing is too expensive (Labro and Vanhoucke, 2007). Christensen (2010) proposes that managers need to be strategic about deciding where to allow less strictly accurate methods so as to focus analytical resources where they might add the most value.

25 Secondly, managerial relevance, depending whether cost information is considered useful for the provider level's management process. The more detailed cost objects are introduced into the cost 
analysis, the more useful it appears for managers (Pizzini, 2006). Managerial relevance may even lead physicians to change their resource utilization patterns of treating patients (Da Silva Etges et al., 2020; Angelé-Halgand and Garrot, 2014; and Eldenburg et al., 2010). In addition, managerial

30 relevance seems to be associated with hospitals' profitability. (Pizzini, 2006).

Thirdly, the costing approach in terms of standardization across provider organizations (Busse et al., 2013). A lack of standardization of costing practices across provider organizations leads to costing variation. Heterogenous definitions of costs, for example, may cause such variations (Himmelstein et al., 2014). These variations are problematic (Northcott and Llewellyn, 2004; and 35 Malcomson, 2007), particularly when cost information is used for tariff setting (e.g., in DRG-based payment systems), as the obtained tariff fails to appropriately reimburse hospitals for services provided (Tan et al., 2014; and Vogl, 2012). Such variation also makes comparisons of clinical procedural costs difficult, even within a country, let alone across countries.

Increasing cost pressures and demands for transparency in public health expenditure have led to 40 greater attention to cost information. While cost reporting is subject to regulation in many countries, the interaction between such regulation and the use of cost information is a relatively new field of research (Labro and Stice-Lawrence, 2020; Eldenburg, Krishnan and Krishnan, 2017; Chapman, Kern, Laguecir and Quentin, 2016; and Chapman, Kern, and Laguecir, 2014). Accordingly, there is a need to better understand these dimensions of cost information quality at 45 the provider and national levels in order to manage the quality of cost information (De Araujo et al. 2019). Therefore, this paper's research question is: how can the quality of cost information be managed?

In the next section, we review the literature to analyze how quality cost information might be conceptualized and achieved. We then report on a study undertaken to analyze clinical costing 50 approaches in seven countries. We find considerable diversity of approaches. Having set out our findings on the nature of this diversity, we then relate these findings to our analysis of the extant 
literature to point out the complexity of trade-offs between the quality of cost information, the costs of collecting and analyzing it, and the different purposes to which it might contribute. We conclude with a proposal for how a two-dimensional Materiality and Quality of Cost Score (2D MAQS) approach can support both regulators and providers in understanding how and where clinical costing might enhance financial and clinical decision making.

\section{Conceptualizing and achieving quality in clinical cost information}

This section explores findings from the research literature around the three dimensions of cost information quality, i.e., cost accuracy, the costs' managerial relevance at the provider level, and

60 standardization across provider organizations. All three dimensions are matters of direct concern for regulators in this field and, in analyzing the literature, we examine basic cost analysis approaches and how these relate to the three identified dimensions of quality of cost information.

\section{Accuracy of cost information}

Accuracy of costs concerns the accurate allocation of costs at the cost objects' level and constitutes a general problem in the management accounting literature (e.g., Labro and Vanhoucke, 2007). Depending on the method used for attributing indirect costs to cost objects, the costs recorded at the cost object level may vary (Laguecir, Chapman and Kern 2020).

Tan et al. (2009, 2014) distinguish four methods to allocate costs at the cost object level, i.e., bottom-up microcosting, top-down microcosting, bottom-up gross costing, and top-down gross costing. In contrast, we rely on the distinction between two methods commonly found in the management accounting literature, i.e., traditional volume-based costing and activity-based costing (Cooper and Kaplan 1998, and Mohr 2017). Bottom-up costing refers to the methodological choice to aggregate the cost of the chosen cost object from costs analyzed at a lower level of aggregation than the cost object. (Please see the cost vocabulary section for further explanations.) 
object from costs analyzed at a higher level of aggregation than the cost object. (Again, please see the cost vocabulary section for further explanations.) We argue that the distinction between bottom-up and top-down costing is independent of the methodological choice of traditional volume-based costing and activity-based costing.

80 Traditional costing allocates indirect costs to cost objects based on volume. The cost driver is calculated by dividing indirect costs by the allocation base, e.g., direct costs. The advantage of traditional volume-based costing is the relatively fast and straightforward calculation of cost drivers and, consequently, the allocation of related costs at the level of cost objects. Its disadvantages lie in relative inaccuracy, as the method assumes a direct relation between direct and indirect costs, which is often not the case. This especially occurs when hospital information systems are not sufficiently developed to trace all resource consumptions at the patient level, which leads to a relatively massive proportion of indirect costs.

Cooper and Kaplan (1998) conceptualized an alternative way of allocating indirect costs to cost objects, called activity-based-costing (ABC). Whilst they wrote many individual articles, their most comprehensive discussion drawing things together on $\mathrm{ABC}$ is the book published in 1998. Within this approach, cause-and-effect relationships are established between indirect costs and cost objects. Indirect costs are attributed to cost objects based on cause-effect relationships and, thus, based on costs caused by the cost object. Consequently, costs attributed to $\mathrm{ABC}$ at the level of cost objects are more accurate than traditional volume-based allocation, where costs are allocated more randomly based on the assumption that indirect costs increase with the volume of direct costs or turnover. This especially applies to organizations with a relatively high share of indirect costs and various cost objects, as is the case for a health care provider.

Although scholars praise $\mathrm{ABC}$ 's advantages, $\mathrm{ABC}$ adoption rate is lower than expected. Analyzing the implementation of $\mathrm{ABC}$ across hospitals in Ireland, it was found that, of the 20 hospitals that 100 had responded to a survey of 60 hospitals, only two had implemented ABC across all units, and 
$55 \%$ had implemented it in selected units (Doyle et al. 2008). Similar results were found in a study of 52 U.S. providers, where adoption rates had dropped from $16 \%$ to $14 \%$ within ten years (Lawson 2005). This observation of the academic literature praising ABC, on the one hand, and on the other hand relatively low adoption rates, has been labeled the ABC paradox (Gosselin 1997).

Some of the explanations advanced for this paradox were, among others, I.T. related issues, lacking involvement of operational staff, and problems updating ABC data (Kaplan and Anderson 2003, and Lawson 2005). These hindering factors have led to the development of Time-Driven ActivityBased Costing TDABC (Kaplan and Anderson 2003), which is an allocation method to make the bottom-up approach more reliable and easier to implement. Costs are here captured at the

110 department or unit level and then divided by the number of total minutes corresponding to that department's theoretical capacity. The implementation costs of TDABC are lower than those of $\mathrm{ABC}$.

Kaplan and Porter (2011) argue that the implementation of TDABC could solve the problem of healthcare, as cost data are often of poor quality since they are mostly based on traditional volume-

115 based costing. The accuracy of cost data that can be achieved with a TDABC at patient-level results in more accurate data at aggregated levels, e.g., at service-line, departmental, or DRG-level (Da Silva Etges et al. 2020; and Keel et al. 2017). This has advantages for providing accurate and transparent data for decision-making at the provider level, as well as for price-setting objectives at the policymaker level.

120 As many countries have the objective of regulating pricing for DRGs, there is a need for more accurate costing information, necessitating the development of costing systems that produce accurate costs (Mercier and Naro, 2014). Since costing systems influence the identification and development of DRGs (Chapman, Kern, and Laguecir, 2014), with more accurate data could revolutionize health care economics (Kaplan and Porter 2011). Whereas much of the academic 125 literature and many textbooks suggest that cost systems are either traditional-volume based, ABC 
or $\mathrm{TDABC}$, recent research shows that in practice, many costing systems are mixtures (Chapman et al., 2013; and Mohr 2017), also referred to as hybrid costing systems (Mohr, 2017).

\section{Managerial relevance of cost information at the provider level}

Managerial relevance relates to whether cost information is considered useful for the provider

130 level's management process. An empirical study across 277 US hospitals showed that the more detailed cost objects are provided for the cost analysis, the more useful this appears for managers (Pizzini, 2006). Next to detail, the study suggests that relevance was linked to a better classification of costs according to behaviour and a more frequent reporting of cost information for managers. This would suggest that frequent reporting based on $\mathrm{ABC}$ or TDABC are judged more relevant as 135 those methods provide more detailed cost information related to cost behaviour.

Pizzini finds that more detailed cost information leads to reduced administrative costs and increased revenue per bed (2006). In the same vein, Ittner, Lanen, and Larcker (2002) show an association between cost system design and successful performance management. The study's empirical data are based on a cross-sectional sample of manufacturing plants. This shows that $\mathrm{ABC}$

140 alone does not then bring about cost reductions. Instead, cost system design is indirectly linked to cost management requiring processes to be in place at operational levels managing cycle time, quality, and cost.

Similar results were found in the healthcare sector. Campanale, Cinquini, and Tenucci (2014) study the potentialities of TDABC in supporting "transparency" and "resource allocation" in public

145 hospitals. In an interventionist research approach, they analyze TDABC implementation in an Italian hospital. They find that TDABC enhances transparency and supports decisions contributing to a better work organization and informed resource allocation. A recent review of 26 articles on TDABC in surgical contexts confirms that TDABC supports clinicians and managers in decision-making (Da Silva Etges et al. 2020). In the same vein, a case study by Eldenbourg et 
150 al. (2010) examines the physician's response to the implementation of an ABC that was developed and designed with physician input. They show that managerial relevance leads physicians to change their resource utilization patterns for patients' treatment and that managerial relevance seems to be associated with hospitals' profitability (Eldenburg et al., 2010).

The most valuable cost data for clinicians are data at the patient-level. At the patient level, cost data can be linked to patient health outcome data, making the link with value-based healthcare creation more apparent. Porter argues that cost data are most relevant at the patient level as they can be related to value (2010). He defines value as patient health outcomes achieved relative to the costs of care. Kaplan and Porter contend that providers should focus on individual patients' costs over their full cycle of care (2011), rather than just single hospital stays or cost analysis at the

160 specialty or service department level. It is patient-level costing over the full cycle and across different providers that must be matched with health outcomes (Kaplan and Porter, 2011). These are the data that would be arguably most relevant for clinical and managerial decision-making.

However, cost data's relevance depends not only on the cost system design. As healthcare is a quite regulated sector in many countries, the regulatory framework influences costs' relevance.

165 Political agendas and purposes may, thus, interfere with managerial relevance (Flury and Schedler, 2006). In particular, New Public Management (NPM) as a political agenda has tried to prioritize costing and other managerial tools for decision-makers in the healthcare sector (e.g., Kurunmäki and Miller, 2006), making it relevant for day-to-day management. Apart from institutional pressures, administrative traditions may play an essential role in the relevance of cost data. 170 Kurunmäki (2004) points out that administrative traditions in different countries can influence cost data use. With no institutional presence of a professional body for management accounting in Finland, doctors adopted cost accounting techniques to manage healthcare services. They readily recognized the relevance of cost data for managing clinical services. 
In contrast, early research in the U.K. has highlighted the potential for conflict between the

175 financial and clinical professions. Even with NPM on top of the agenda, medical professionals resisted accounting practices' intrusion into the medical domain (Kurunmäki, 2004). The professional body of management accountants being strongly developed in the U.K., doctors opposed the adoption of management accounting techniques within their professional medical field. Similarly, Ferlie and Fisher (2013) offer further evidence of clinicians in the U.K. resisting 180 management accounting. To remedy this, patient-level-information and costing systems (PLICS), integrating financial and clinical information at the patient level, have been introduced to better align financial and clinical perspectives. PLICS is thought to gradually replace the top-down reference costs. To support the development of PLICS, the Healthcare Costing for Value Institute was founded by the HFMA, to develop methods to drive value-based healthcare, meaning "maximizing the outcomes at the lowest possible costs" (HFMA, 2020).

While in six of the observed countries costing guidance was managed over time by the same institution, we observe changing responsibilities in England, with various roles at different points played by the Department of Health, the Healthcare Financial Management Association, and Monitor which was subsequently evolved into NHS Improvement.

190 Thus, administrative traditions in a jurisdiction heavily influence how cost data or other management accounting techniques are used and considered relevant to decision-makers. Mohr et al. (2020) reinforce this analysis when comparing cost accounting across 19 European countries. They underline how NPM is a major driver of government cost accounting, but the government's administrative traditions also influence the use of cost accounting and, therefore, its relevance.

195 Finally, variations of relevance in terms of cost data can be found across space and time. For instance, Laguecir, Chapman, and Kern (2020), studying the case of a social housing firm in France, show how different public sector regimes in France influence the understanding of costs and their use. 
Standardization of cost information across provider organizations

200 Cost accounting data in healthcare is used at the provider level and informs decision-making at policy and, therefore, at regional and national levels. The primary purpose for using cost data is price-setting for DRGs at the governmental level. However, costing is not subject to mandatory adherence to standards as in financial accounting; costing practices vary between different provider organizations, not only between countries but within the same country. Such variation creates 205 problems at the policy level (Northcott and Llewellyn, 2004; and Malcomson, 2007). Cost variation is a significant obstacle for fair prices, as prices are supposed to reflect resource consumption. Malcomson (2007) identifies four reasons for cost variations among providers: providers' inherent cost characteristics; economies of scale; case-mix; and management practices. Inherent cost characteristics are, for example, differences in land costs among providers. Economies of scale are

210 achieved by the volume of patients treated; smaller units have higher costs per case due to lower volume. Differences in case-mix, such as the proportion of patients treated as day cases instead of in-patients, also cause variations in costs. Management practices affect the efficiency of services, which may vary and lead to cost differences.

Not mentioned by Malcomson (2007) is the fifth cause of variation, namely: differences in costing 215 methodologies. As explained in the previous section on accuracy, the choice of ABC or traditional volume-based costing or a specific mix of both costing methodologies leads to differences in costs at the cost object's level, i.e., the patient. Different definitions of costs may also cause variations, e.g., ward administration, a central administrative cost or operational administrative cost, and a different healthcare organization structure itself (Himmelstein et al., 2014). A recent study on the 220 quality of cost data across Danish hospitals observes variations of definitions of costs and differences in allocation methods at the department level between hospitals (Malmmose and Lydersen, 2020). Furthermore, the study finds a melding of both overhead and indirect costs with direct costs at the department level. Interestingly the study points out that often aggregate 
information is not tied to patient information, thereby not respecting national guidelines

225 (Malmmose and Lydersen, 2020) and, thus, being decoupled from the policy level (Kern, Lacuecir and Leca, 2018)

This is an obstacle for tariff setting purposes at the policy level which requires standardization of costing data and costing practices across provider organizations (Busse et al., 2013). Without standardization costs for different procedures, the tariff does not convey meaningful information 230 and cannot be used to identify inefficiencies.

Tan et al. (2014) have analyzed European countries' cost accounting systems within the Euro DRG project. They find that costing systems vary widely in the share of hospital costs reimbursed through DRG payment, the presence of mandatory cost accounting and/or costing guidelines, the share of cost collecting hospitals, costing methods, and data checks on reported cost data. They 235 argue that each of these aspects entails a trade-off between the accuracy of the system's cost data and feasibility constraints. More specifically, they identify three trade-offs.

The first trade-off concerns the share of hospital costs reimbursed through DRG payment. A large share increases the relative importance of any DRG system and the comprehensiveness of the cost database. However, it may jeopardize hospital service delivery's primary objectives, such as by 240 prioritizing efficiency over the quality of healthcare services. The second trade-off concerns the share of cost collecting hospitals (Tan et al, 2014). A small number of costs collecting hospitals with standardized cost accounting systems will lead to a higher quality of cost data. A large number of cost collecting hospitals may provide a more comprehensive picture of differences in the severity of cases or hospitals' structure in a particular country during the calculations. However, 245 costing may lack standardization and, therefore, quality. The last trade-off relates to costing methods, such as bottom-up versus top-down micro-costing (Tan et al. 2009; 2014). Tan et al. (2014) argue that a bottom-up microcosting approach across providers may be the only way to truly measure, compare, and improve the efficiency of hospital service delivery. 


\section{Analyzing approaches to clinical costing in seven countries}

250 To develop their understanding of these issues, the research team undertook a structured collection of data regarding healthcare costing guidance for acute care in seven countries (Denmark, England, France, Germany, Ireland, the Netherlands, and Portugal). The countries were selected to represent typical characteristics of western European healthcare systems. The sample comprises countries with social insurance systems such as France, Germany, and the Netherlands, and tax-based NHS systems such as Denmark, Portugal, England, and Ireland.

The researchers collected data via a jointly developed questionnaire on costing guidance. For this purpose, researchers gathered the official costing guidance for their jurisdiction (Table 1) and relevant secondary documents. Also, interviews with regulators, guidance setters, and costing experts were carried out for specific questions. An initial data collection took place in 2012 and

260 the collected data was updated at the end of 2020.

\section{Insert Table 1 here}

The questionnaire was developed around two independent aspects of costing approaches that affect quality: 1) the purposes of costing systems and their integration with the regulatory framework, and 2) the costing method adopted. A challenge in undertaking this analysis is that the vocabulary and concepts around costing guidance are often only partially defined, particularly in terms of the costing method. This complicates international comparisons of costing guidance. For instance, the labels used to characterize costing guidance or costing systems (e.g., a top-down costing system) are often not precisely defined. 
To address this issue in our study, in the glossary section (please see Table 6 cost concepts glossary) we define the main concepts around costing guidance used in this report and data collection. This study's specific definitions are drawn from the DRG and costing system's conceptual framework as defined in the relevant literature (Chapman and Kern, 2010; and Busse et al, 2011).

275 The data analysis was initially carried out by a single researcher to ensure consistency, and this was subsequently checked by the others. The preliminary results were presented and discussed at a workshop organized in November 2012, attended by the entire network and a range of U.K. healthcare costing practitioners and regulators. The results were published in a report to policymakers (Chapman et al., 2013). 


\section{Findings}

Purposes of costing systems and their integration with the regulatory framework

In most countries, costing information that is produced based on costing guidance is used for three main officially stated purposes: 1) internally at the provider level to produce cost reports; 2) to inform prices at national levels; and 3) as a benchmark, not only within the provider organization, but with other providers. Table 2 gives an overview of the purposes of costing across the seven countries.

\section{Insert Table 2 here}

290

In most countries, the purpose of clinical costing is closely linked to the development and updating of the DRG-based payment systems. In all countries, cost information is used to calculate or adjust DRG weights, and several countries also use cost information for the development and refinement of DRGs. (Please see the last column in Table 2.)

295 Due to the purpose of informing DRG-based payment systems, regulators seek to decrease variation in costing practices across providers to make costs more comparable. An essential tool used by regulators to achieve this is mandatory costing guidelines. The mandatory costing guidelines (edited by regulators and government), shape cost system design at the provider level. This external influence on cost system design is a specific characteristic of the healthcare sector.

300 Across most countries, the development of costing guidance was driven by the introduction of the funding system. Governments' interest in a fair funding system is often a dominant motivation for introducing costing guidance. Nonetheless, the managerial relevance of costing can conflict with tariff setting and related standardization, leading to trade-offs between these purposes. 
The seven countries have different approaches regarding the number of providers applying cost

305 guidance (see Table 3). In some countries (Denmark and France), all providers have to adhere to the costing guidance, and the cost information of all providers is collected (Denmark and France). In other countries (e.g., Germany, Ireland, and the Netherlands), not all providers adhere to the same guidance. In England, all providers have to adhere to HRG-form costing (HRG are the UK DRGs), with PLICS now mandatory in the acute sector with plans to make it mandatory more 310 widely. Cost information from only a sample of them is collected and informs the tariff calculation. These providers must follow the patient level costing guidance, and their compliance is verified. The sampling approach is driven by economic criteria or left to the site's discretion. For example, in France, all sites have to conform to unique costing guidance, but each hospital can choose whether or not to be part of the sampling informing the tariffs.

315 When the number of providers is relatively high, as in Germany, sampling can decrease the cost calculation process's overall costs. The cost associated with the control of guidance compliance is also lower.

In all countries following the sampling approach, participation in the sample is voluntary. Therefore, the sample representativeness cannot be ensured. The regulator can only reject a volunteering organization wishing to participate in the sample. Providers with relatively low average costs across the board may also not participate in the sample so as not to drive down the DRG weight and benefit in this way from a relatively high tariff. In terms of sample size, approaches vary widely across countries. 
The relationship between the costing system and the regulatory framework differs across countries. In some countries, such as England, only high-level accounts of the chart of accounts are mandatory. The detailed accounts used in hospitals may then differ from one hospital to another. Although recently some attention has been given to how to introduce more standardisation to the relationship between the general and costing ledgers.

In other countries, e.g., Germany and France, a detailed chart of accounts is mandatory to ensure that all hospitals use the same accounts. This detailed chart of accounts can then be used to define the costing guidance (see Table 4).

\section{Insert Table 4 here}

340 information required, thereby influencing the types of cost, cost pools, and cost drivers. In turn, the analysis of cost information is the basis for the refinement of DRG systems.

\section{Costing method adopted}

A costing method is characterized mainly by the nature of the cost object, the way costs of a cost object are aggregated or disaggregated, top-down or bottom-up, and the treatment of the

345 indirect costs, i.e., activity or volume-based. The cost objects supported by costing guidance include the DRGs, the specialty/service-line, and the patient. These cost objects are linked to different levels of enforcement (see Table 5). Patient-level costing guidance is mandatory in three countries: Germany, Denmark, and the Netherlands, at least for a sample of hospitals. Ireland is running a pilot study on patient-level costing at some 15 pilot sites. 
Some countries employ specific costing guidance in place for different cost objects. For example, two countries (England and Ireland) have DRG level costing and have started implementing optional patient-level costing. In England meanwhile patient-level costing has become mandatory for the acute sector and it is planned to become the norm for all sectors.

This move is motivated by the expectation of obtaining more accurate cost information and making costs more manageable. These two countries have two pieces of guidance in place, i.e., costing guidance for mandatory DRG and specialty-level costing, and costing guidance for patientlevel costing. The existence of two sets of guidance is also observed in sampling systems. For example, in Germany, there is a mandatory cost centre level costing for all providers and a mandatory patient-level costing for providers of the sample informing the DRG costing.

\section{Insert Table 5 here}

Concerning the aggregation and disaggregation of costs and the treatment of indirect costs, we find that, in general, the costing guidance is a mixture of different methods. For example, the 365 German patient-level guidance offers two options for the treatment of costs of executive management. One option suggests that executive management costs (indirect costs) should be attributed to direct (patient-related) cost centres based on the primary direct costs. This corresponds to a top-down volume-based costing. The other option states that these costs should be attributed to direct cost centres based on the number of full-time employees, which is also top-

370 down volume-based costing. The volume here does not refer to the number of units produced, but rather to production resources. However, for other indirect costs, e.g., the operating theatre, the German guidance proposes bottom-up activity-based costing. Costs in the operating theatre are calculated based on theatre minutes, considering re-tooling and labor intensity (the hours 
worked by staff for the operation). Therefore, costing guidance and costing systems at the provider

375 level consist of a mix of methods, i.e., top-down/bottom-up and volume/activity-based costing.

\section{Relating findings to analysis of dimensions of quality from the literature}

This study answers recent calls on studying the interaction between regulation and costing (Chapman, Kern, and Laguecir, 2014; Eldenburg, Krishnan and Krishnan, 2017; and Labro and Stice-Lawrence, 2020) with a specific focus on the quality of costing information (Hrifach et al., 2018). In seeking to analyze regulatory approaches to costing across seven countries, we developed a framework for analysis in terms of: 1) the purposes of costing systems and their integration with the regulatory framework; and 2) the costing method adopted. Building upon differences between countries reported in our results, this section discusses how this impact the quality of cost information.

385 The tariff setting purpose is dominant at the regulatory level, requiring standardization. As underlined by several studies (Malmmose and Lydersen, 2020; Audit Commission, 2012, and Vogl, $2013,2012)$, such standardization of costing is difficult in practice for regulators to achieve due to the high costs of implementing standards and collecting and auditing cost information. Moreover, there are difficulties observed in implementing guidelines at the provider level. These difficulties

390 go so far as costing practices in hospitals being decoupled from national guidelines (Malmmose and Lydersen, 2020; and Kern, Laguecir and Leca, 2018).

Standardization may also stand in the way of making costing relevant for decision-making at the clinical unit level, another important objective for policymakers. Using costs for management requires costing to have managerial relevance and, therefore, to be specific to frontline staffs needs. There is currently little guidance for providers on making cost information relevant to management at the clinical unit level. Exceptions are England (NSI, 2020) and France (MeaH 2009, ANAP 2015, ATIH 2019). NHS Improvement following the early lead of HFMA has led a 
major overhaul of costing during the period, with a costing transformation programme aimed at furthering the relevance of costing for Managerial decision making.

400 To this we can add to Vogl (2012), who points out that, while bottom-up costing in Germany increases the quality at the managerial level, there is still a problem in the quality of the data for tariff setting due to the composition of the sample. In fact, we identify a trade-off between two dimensions of quality of costing, i.e., standardization and managerial relevance. Integrating both of these purposes at the regulatory level within costing guidance would support the managerial 405 relevance of cost information at the clinical unit level where key-decision-making takes place. Producing cost information for both purposes may require two cost systems at the provider level: one serving standardization and the other serving managerial relevance. The French case, where the cost information produced for standardization is proposed at the same time as support for hospital managers, is illustrative of the two-in-one approach.

410 Equally, the quality of costing could be managed by integrating costing and the chart of accounts to enhance accuracy and standardization. Firstly, this integration supports management accountants at the provider level when designing cost systems, as it eases the reconciliation of cost information and the general ledger, thus improving the accuracy of cost information at the provider level. Secondly, this integration supports standardization of costing practices and,

415 therefore, cost data use at national levels. If there is no mandated detailed chart of accounts, costing guidance leaves room for variation in linking specific accounts with the cost pool structure. However, such a standardization of the chart of accounts may compromise the managerial relevancy of the accounts at the provider level. Thus, leading to another trade-off between standardization and managerial relevance.

420 Furthermore, the quality of costing can be managed by introducing sampling, meaning rather than taking cost data from all providers into account, selecting a sample of hospitals that will provide cost data for tariff setting purposes. Sampling supports the standardization of cost information. 
Nevertheless, while sampling also reduces the costs of producing cost information and controlling its quality, it raises the issue of providers' representativeness. Some of the characteristics that may influence the sample's representativeness are the number of public and private providers and small and big providers. Being a public or private hospital may influence the cost structure, while the hospital's size has an economic influence in terms of economies of scale and scope. This has led some countries, like France, to develop two separate samples and tariff grids: public and non-profit hospitals; and private for-profit hospitals.

430 As these characteristics influence the costs of a provider, they affect the reported costs of the sample. For example, providers with relatively low costs may not participate in the sample so as not to decrease the tariff and profit from a relatively higher tariff. Therefore, sampling may not necessarily improve the quality of cost data at the national level, i.e., the tariff's quality, if the sample does not accurately represent hospitals' mix in the total sample. Consequently, the trade-off to 435 consider here is that between standardization and accuracy of costs.

Costing quality can also be managed by introducing specific costing methods, which may impact all dimensions of costing quality, i.e. accuracy, relevance at the provider level and standardization at the regulatory level. The costing methods set out in the national guidelines vary greatly across the seven countries. While always consisting of a mix of both bottom-up and top-down and volume and activity-based methods, the guidance differ in how the methods are mixed.

Firstly, costing methods impact accuracy. Regarding accuracy, bottom-up costing allows accounting for more accurate costs at the patient level. Top-down costing, which is based on averages, is faster and more easily implemented but produces less accurate cost information at the patient level (Porter and Kaplan, 2011). Volume-based costing entails another disadvantage in 445 terms of accuracy: changes in volume in one unit can potentially impact other units. In contrast, activity-based costing, establishing cause-and-effect relationships between indirect costs and 
activities, can avoid this source of variation, allowing costs of unused capacity to be directly analyzed.

Secondly, costing methods impact managerial relevance. Bottom-up costing produces cost information that varies across patients, which can then be more easily linked with clinical outcomes and, therefore, serve to calculate the value produced, making such information particularly relevant for clinical decision-making (Porter and Kaplan, 2011). Bottom-up is also more flexible as it more easily allows for the introduction of new cost objects (e.g., patient trajectory). Top-down costing, relying on averages, makes it difficult to relate clinical outcomes and costs meaningfully at the patient level and is, consequently, less relevant for decision-making at the provider level.

Thirdly, costing methods impact standardization. Standardizing bottom-up costing across providers is resource-intensive, while it is faster and more easily achieved with top-down costing. Yet the impacts of efficiency driven through tariff grids do not take quality issues into account and should be further investigated. France would provide a good basis for this with its top-down 460 method designed for standardization purposes and putting strong pressure on clinical teams to increase activity volumes with some adverse side effects on quality and professional, ethical tradeoffs (Angelé-Halgand and Garrot, 2014).

To sum up we, observe that the choice of costing methods impacts all three dimensions of the quality of costing, entailing trade-offs between accuracy, managerial relevance at the provider level and standardization. Here we contribute to the discussion on trade-offs regarding cost information quality (Tan et al., 2014). Tan et al. (2014) identify trade-offs between the accuracy of cost data and feasibility constraints. We propose that accuracy is only one dimension of the quality of cost information, the other two dimensions being managerial relevance at the provider level and standardization across provider organizations. We then suggest, in contrast to Tan et al. (2014), that there are trade-offs within these three dimensions of quality of cost data, that is, between accuracy, managerial relevance, and standardization. 
Here, our study complements that of Tan et al. (2014) by re-defining cost vocabulary. The categories of cost allocation methods underlying the Tan et al. (2014) study, i.e., the categories of bottom-up microcosting, top-down microcosting, bottom-up gross costing, and top-down gross costing are, in our view, imprecise and potentially misleading. As outlined in Table 6 definitions for cost vocabulary, we suggest distinguishing between bottom-up and top-down costing, and noting that costing systems are often a mixture of both methods (Chapman et al., 2013, 2016). We reinforce the findings of Chapman, Kern, Laguecir, and Quentin (2016) and Mohr (2013, 2017), suggesting that we often find mixtures of both methods and therefore hybrid costing systems in

480 practice.

\section{Conclusion}

Policymakers need to manage the complex trade-offs between the different dimensions of cost quality, i.e., accuracy, managerial relevance at the provider level, and standardization. To do so, the various rules, guidances, and systems influencing costing must be carefully integrated. Costing 485 guidance, the DRG system, and financial accounting are often under the responsibility of different instructional actors, making it difficult to consider their inter-dependence. A potential step for managing the quality of clinical costing would be integration at the institutional level. An integrated approach to costing guidance and patient classification systems may allow for better coordination of both elements' development, and enable potential synergies to be realized, both at organizational and technical levels. Therefore, policymakers might integrate costing guidance and DRG systems, as for example in Germany within InEK. ${ }^{1}$ However, integration may also be

\footnotetext{
${ }^{1}$ Taking integration to its logical conclusion, Germany created a single actor responsible for the main elements of the hospital payment system, including clinical costing. Germany is a jurisdiction with a universal multi-payer healthcare system, marked by public and private insurance, public and private providers, and different regional and national budgets. Yet all players agreed to create a new organization in 2001 (InEK) that would be responsible for developing the hospital payment system, defining and updating bottom-up patient level costing guidance. The responsibility for the development of patient classification systems and costing guidance falls here under the same umbrella.
} 
achieved by considering the interdependencies between costing guidance, DRG systems, and financial reporting, without necessarily creating a single organization.

Whether or not they are integrated in a single organization, due to the various trade-offs we have 495 identified, policymakers can not follow through on all dimensions of quality of costs simultaneously. Instead, they must make choices entailing compromises. Providers may be at different stages in their costing process. Some have implemented $\mathrm{ABC}$ costing for a large part of their indirect costs, while others are just starting to implement Patient Level Information and Costing Systems (PLICS), and not yet at the stage of exploiting their cost data in decision making.

500 This impacts the objectives at the regulators' level of standardization for tariff setting and sampling. We argue here that it is not only standardization that can make costing more transparent in such a context. Instead, regulators, policymakers, and practitioners at the provider level alike could benefit from more transparency regarding where exactly the hospitals stand. To this end, hospitals could calculate the part of indirect costs that are handled with activity-based drivers and the part of costs

505 handled with volume-based costing, as done with the MAQS in England (HFMA, 2013).

MAQS calculates the proportion of costs calculated with activity-based and traditional volumebased costing setting out a series of cost pools. The score is derived by quality weighting the quantum of cost in each cost pool according to the cost driver's appropriateness (HFMA 2013). Whilst this focuses attention on the detail of costing simply and intuitively, the tool directs 510 attention to cost drivers and not so much cost pool structure, however, although this is an important aspect of achieving a true cause and effect relationship in cost analysis. For example, clinical staff costs might in principle be more accurately traced using patient minutes. However, if the costs of different categories of staff performing different activities are aggregated into one large cost pool, then dividing by patient minutes produces a less accurate cost for a cost object 515 than if staff cost is broken down into sub cost pools and separate patient minute rates calculated. 
In this respect, an interesting evolution is that MAQS is to adopt a two-dimensional (mapping resource costs into activity costs) matrix structure to frame analysis of cost driver options (as also discussed in Chapman, Kern, Laguecir and Quentin, 2016). This evolution of MAQS would enable detailed discussion of the trade-offs between dimensions of cost quality since decisions about whether a particular intersection of resource and activity costs is either financially and/or clinically material can inform decisions about the benefits of investing in more detailed and precise cost drivers. At the provider level, conversations around these matters can act to drive targeted local improvements to costing systems where they can generate specific benefits. At the policy level, regulators can use the profile of quality weights to focus collective attention on particular areas

525 and allow for different levels of preparedness of individual providers to move towards higher quality costing systems.

Regulators could also use a 2D MAQS to manage the many trade-offs between quality and cost of costing underlying the decision to impose tariffs based on only a small sample of providers in some countries. Germany, for example, samples a small proportion of providers and has extremely high-

530 quality demands. The providers not included in the sample may have a wide range of quality of costing and, absent a regulatory requirement, might be missing out on the possibilities for service improvement a costing system might offer. A 2D MAQS approach would allow regulators to direct the attention of all providers towards the benefits of costing information whilst also allowing for the prioritization of accuracy in costs informing tariffs. Whilst making a requirement for a return 535 of cost data from all providers, a hurdle level of quality to qualify for inclusion in the tariff setting sample might be set. Given that the tool also promises to drive local quality improvements in cost systems and service delivery, this would offer the potential for the sample making up the tariff to grow over time as more and more providers reached the threshold.

Finally, for practitioners in hospitals and policymakers and regulators at national levels, it would 540 be interesting to know the proportion of costs calculated after one or the other methods to 
enhance the value and reliability of international comparisons of cost data (Himmelstein et al., 2014).

We conclude with a reminder that more research on these matters is needed and that our findings must be interpreted with caution. This study's focus was acute care, and broader clinical practice

545 (e.g., mental health) may impact the results as costs in these areas are less standardizable. Naturally, we also have to be cautious regarding how far our results can be generalized, as the number of countries examined is limited to seven. Finally, the study dealt with guidance, which may differ from the provider level's actual costing practices. However, as the ultimate usefulness of costing guidance is determined by its use at the provider level, this should be a focus of future research. 


\section{References}

Audit Commission, Right Data, Right Payment: Annual Report on the Payment by Results Data, Assurance Programme, Editor. 2012, Audit Commission: London.

560 ATIH, Méthode alternative à la comparaison des coûts et des tarifs—guide méthodologique, Nov 2019. 18. p. Available from: https://www.atih.sante.fr/methode-alternative-la-comparaison-descouts-et-des-tarifs-campagne-tarifaire-2019

Busse, R. et al. (2013) "Diagnosis related groups in Europe: moving towards transparency, efficiency, and quality in hospitals?,” Bmj. British Medical Journal Publishing Group, 346, p. f3197.

565 Busse, R., Schreyögg, J. and Smith, P. C. (2008) "Variability in healthcare treatment costs amongst nine E.U. countries-results from the HealthBASKET project," Health economics. John Wiley \& Sons, Ltd. Chichester, UK, 17(S1), pp. S1-S8.

Campanale, C., Cinquini, L., \& Tenucci, A. (2014). Time-driven activity-based costing to improve transparency and decision making in healthcare: a case study. Qualitative Research in Accounting 570 \& Management, 11(2), 165-186.

Chapman, C. S. and Kern, A. (2010) "Costing in the National Health Service: from reporting to managing." London: Imperial College London.

Chapman, C. et al. (2013). "International approaches to clinical costing." Healthcare Financial Management Association (HFMA).

575 Chapman, C., Kern, A. and Laguecir, A. (2014) "Costing practices in healthcare." Accounting Horizons. American Accounting Association, 28(2), pp. 353-364. 
Chapman, C. S., Kern, A., Laguecir, A. and W. Quentin (2016). "Management accounting and efficiency in health services: the foundational role of cost analysis," in Health system efficiency: how to make measurement matter for policy and management. World Health Organization.

Christensen, J. (2010). Accounting errors and errors of accounting. The Accounting Review, 85(6), 1827-1838.

da Silva Etges, A. P. B., Ruschel, K. B., Polanczyk, C. A., \& Urman, R. D. (2020). Advances in value-based healthcare by the application of time-driven activity-based costing for inpatient management: a systematic review. Value in Health.

Doyle, G., Duffy, L., McCahey, M. and Schools, U.B., 2008. An empirical study of adoption/nonadoption of activity based costing in hospitals in Ireland. Administration Sciences Association of Canada, Dalhousie University, Canada, pp.24-27.

de Araujo, T.R., Papathanassoglou, E., Menegueti, M.G., Auxiliadora-Martins, M., Bonacim,

590 C.A.G., do Valle, M.E.L. and Laus, A.M., 2019. Urgent need for standardised guidelines for reporting healthcare costs in ICUs-Results of an integrative review of costing methodologies. Intensive and Critical Care Nursing, 54, pp.39-45.

Eldenburg, L., Soderstrom, N., Willis, V., \& Wu, A. (2010). Behavioural changes following the collaborative development of an accounting information system. Accounting, Organizations and 595 Society, 35(2), 222-237.

Eldenburg, L. G., Krishnan, H. A. and Krishnan, R. (2017). "Management accounting and control in the hospital industry: A review." Journal of Governmental \& Nonprofit Accounting. American Accounting Association, 6(1), pp. 52-91.

Fischer, Michael Daniel, and Ewan Ferlie. (2013) Resisting hybridisation between modes of clinical

600 risk management: Contradiction, contest, and the production of intractable conflict. Accounting, Organizations and Society, 38 (1), pp. 30-49. 
605 implementation of activity-based costing. Accounting, organizations and society, 22(2), 105-122. HFMA (2020). https://www.hfma.org.uk/our-networks/healthcare-costing-for-value-institute, last accessed on 22.1.21

HFMA (2013). Clinical Costing Standards. 2013

Himmelstein, D. U. et al. (2014) “A comparison of hospital administrative costs in eight nations:

610 U.S. costs exceed all others by far." Health Affairs, 33(9), pp. 1586-1594.

Hrifach, A. et al. (2018) "National cost study versus hospital cost accounting for organ recovery cost assessment in a French hospital group." Cost Effectiveness and Resource Allocation. Springer, 16(1), p. 34.

Ittner, C., Lanen, W., \& Larcker, D. (2002). The association between activity-based costing and

615 manufacturing performance. Journal of Accounting Research, 40(3), 711-726.

Kaplan, R. S., \& Anderson, S. R. (2003). Time-driven activity-based costing. SSRN eLibrary. doi: $10.2139 / \operatorname{ssrn} .485443$

Kaplan, R. S., \& Cooper, R. (1998). Cost \& effect: using integrated cost systems to drive profitability and performance: Harvard Business Press

620 Keel, G., Savage, C., Rafiq, M., \& Mazzocato, P. (2017). Time-driven activity-based costing in health care: A systematic review of the literature. Health Policy, 121(7), 755-763.

Kern, A., Laguecir, A., \& Leca, B. (2018). Behind smoke and mirrors: a political approach to decoupling. Organization Studies, 39(4), 543-564.

Kurunmäki, L. (2004). A hybrid profession—the acquisition of management accounting expertise

625 by medical professionals. Accounting, organizations and society, 29(3-4), 327-347.

Kurunmäki, L., \& Miller, P. (2006). Modernising government: the calculating self, hybridisation and performance measurement. Financial Accountability \& Management, 22(1), 87-106. 
Labro, E. and Stice-Lawrence, L. (2020) “Updating Accounting Systems: Longitudinal Evidence from the Healthcare Sector.” Management Science. INFORMS.

630 Labro, E. and Vanhoucke, M. (2007) “A simulation analysis of interactions among errors in costing systems." The Accounting Review, 82(4), pp. 939-962.

Laguecir, A., Chapman, C. S., \& Kern, A. (2020). Profitability calculations under trial of strength: Insights into intra-accounting variation in a social housing organization. Accounting, Auditing \& Accountability Journal, 33(4), 727-751.

635 Lawson, R.A., 2005. The use of activity based costing in the healthcare industry: 1994 vs. 2004. Research in healthcare financial management, 10(1), pp.77-94.

Linna, M. et al. (2010). "Measuring cost efficiency in the Nordic Hospitals—a cross-sectional comparison of public hospitals in 2002." Health care management science. Springer, 13(4), pp. $346-357$.

640 Malcomson, J. M. (2007). "Hospital Cost Differences and Payments by Results." Health Econ. Pol'y \& L. HeinOnline, 2, p. 429.

Malmmose, M., \& Lydersen, J. P. (2020). Assessing hospital cost data quality in the quest for a cost-effective health care.

MeaH, Nouvelle gouvernance et comptabilité analytique par poles CREA, CREO, TCCM, 645 tableaux de bord, une aide méthodologique au dialogue de gestion. 2009, L'Agence nationale d'appui à la performance des établissements de santé et médico-sociaux (ANAP): Paris. 142 p. Available from: http://ressources.anap.fr/pilotage/publication/2515

Mercier, G., \& Naro, G. (2014). Costing hospital surgery services: the method matters. PloS one, 9(5), e97290.

650 Mohr, Z. T. (2017). A Framework for Cost Accounting Systems in Government. In Z. T. Mohr (Ed.), Cost Accounting in Government: Theory and Applications (pp. 1-26). New York, NY: Routledge. 
Mohr, Zachary T., Ringa Raudla, and James W. Douglas. (2020). Comparing Cost Accounting Use across European Countries: The Role of Administrative Traditions, NPM Instruments, and Fiscal Stress. Public Administration Review.

NHS Improvement (2020)

https://improvement.nhs.uk/documents/6525/Cost_Launch_Event_Slide_deck.pdf (last checked 22.3.21)

Northcott, D. and Llewellyn, S. (2004). Cost variability in health care. Chartered Institute of 660 Management Accountants, London.

Pizzini, M. J. (2006) “The relation between cost-system design, managers' evaluations of the relevance and usefulness of cost data, and financial performance: an empirical study of U.S. hospitals.” Accounting, organizations and society. Elsevier, 31(2), pp. 179-210.

Porter, M. E. and Kaplan, R. S. (2011) "How to solve the cost crisis in health care." Harvard 665 Business Review, 4, pp. 47-64.

Schreyögg, J., Tiemann, O., Stargardt, T., \& Busse, R. (2008). Cross-country comparisons of costs: the use of episode-specific transitive purchasing power parities with standardised cost categories. Health Economics, 17(S1), S95-S103.

Tan, S. S., Rutten, F. F. H., Van Ineveld, B. M., Redekop, W. K., \& Hakkaart-van Roijen, L. (2009).

670 Comparing methodologies for the cost estimation of hospital services. The European Journal of Health Economics, 10(1), 39-45.

Tan, S. S. et al. (2011) "DRGs and cost accounting: Which is driving which.” Busse, R., Geissler, A., Quentin, W., Wily, M.(Eds.) Diagnosis-related groups in Europe: moving towards transparency, efficiency and quality in hospitals. Buckingham, Open University Press and WHO

675 Regional Office for Europe, pp. 59-74. 
Tan, S. S. et al. (2014) "DRG systems in Europe: variations in cost accounting systems among 12 countries." The European Journal of Public Health. Oxford University Press, 24(6), pp. 10231028.

Vogl, M. (2012) “Assessing DRG cost accounting with respect to resource allocation and tariff

680 calculation: the case of Germany.” Health economics review. Springer, 2(1), p. 15.

Vogl, M. (2013). Improving patient-level costing in the English and the German "DRG" system. Health Policy, 109(3), 290-300. 
Dear reviewer 1,

We would like to thank you very much for your constructive comments. We carefully considered them in the revision of the paper. Our responses are indicated below in italics.

1) Section literature review: please verify the possibility to include more recent literature

Thank you for pointing this issue out. In the new version, we added recent literature to the introduction and the theory section. In particular, we refer to the following more recent papers: Hrifach et al., 2018; Mercier and Naro, 2014; Silva Etges et al., 2020; Labro and Stice-Lawrence, 2020; Eldenburg, Krishnan, and Krishnan, 2017; De Araujo et al., 2019.

2) Section Method: I feel difficulties in getting the link between data collected and the dimensions of quality. It would be beneficial with respect to the clarity of the paper to provide a clear connection between sources of data (or questions/group of questions of the questionnaires) and the three dimensions of quality discussed in the paper.

3) Section Presentation of findings: The presentation of result is a characterisation and comparison of the different approaches to clinical costing across 7 jurisdictions. I still find difficulties in capturing the link of the presented findings with the dimensions of quality of cost information, as well as to get the key points that would be object of discussion later in the paper

4) Discussion:

a. The Discussion has improved but it still needs further elaboration. In fact, I still have difficulties in seeing the connection with empirical findings. In particular, how have you been able to discuss the dimensions of quality with evidences presented in your results (in the current version results characterise and compare different approaches to clinical costing across 7 jurisdictions) .

b. Another difficult is getting the dimension of relevance within your empirical data.

c. Recommendations do not follow a presentation of best practices, as I would have expected (the concept of best practices needs also explanations, as stated above).

d. As well as for the section "Result", this section needs major connection with your framework of analysis of quality

e. You discuss a trade-off among the three dimensions of quality. Examples of trade-off are presented around the section. This discussion would benefit if you are able to present trade-off more systematically.

Thank you for these very helpful comments. We carefully considered and addressed them in the new version. We improved the link between empirics and the rest of the paper. To achieve this undertook the following changes:

- We rewrote the abstract.

- We rewrote the introduction, the literature review, the discussion, and the conclusion to align them better while improving the link between the empirical analysis and the dimensions of quality of costing.

- We also changed the headings and subtitles of the different sections to reflect better the link between empirics and the rest of the paper.

We also carried out the following minor changes: 
- we moved the glossary box to the appendix

- we had the text copy edited

\section{Other major points:}

1) Pag. 5 line 135-140: You say that ABC and TDABC may provide more relevant information. Although I agree with this claim, traditional methods when providing detailed and personalized information may as well support relevance.

2) Pag. 6 : You introduce the concept of outcome. It would be interesting to see a brief discussion about this key point in your conclusion.

3) Pag. 6-7: You introduce the discussion about relevance. However the researches you mention do not properly deal with relevance, but they deal with the use/acceptance of managerial tools by physicians and their managerialization/hybridization. Make sure to provide a sufficient discussion about relevance, when mentioning this research. For example, the work by Kurunmaki (2004) discusses the hybridization of medical professions and how the approach to reforms may impact on this phenomena, but she does not discuss relevance.

4) Pag. 18 from line 53: You say that standardization can support relevance. Can you provide better argument for this claim?

Later you argue exactly the opposite, i.e. that standardization limits relevance. Can you provide argumentation for this apparent contradiction?

5) In general, many claims declared are presented in a too much simplistic way and would need a better argumentation

Finally, we addressed all the above-mentioned points.

We hope that with the new version, we now address your comments.

Thank you again for your constructive comments.

Best regards,

The authors 


\begin{tabular}{|c|c|c|c|}
\hline Countries & Costing guidance & $\begin{array}{l}\text { Institution for costing } \\
\text { guidance }\end{array}$ & Institution for DRG \\
\hline Denmark & $\begin{array}{l}\text { Kogebog (Cookbook) and Taktssystem } \\
2012\end{array}$ & $\begin{array}{l}\text { The Danish Ministry of } \\
\text { Health (Ministeriet for } \\
\text { Sundhed of Forebyggelse) }\end{array}$ & $\begin{array}{l}\text { DRG office at the } \\
\text { National Board of } \\
\text { Health }\end{array}$ \\
\hline England & $\begin{array}{l}\text { Approved Costing Guidance } \\
\text { https://www.england.nhs.uk/approved- } \\
\text { costing-guidance/ }\end{array}$ & $\begin{array}{l}\text { National Health Service } \\
\text { Improvement }\end{array}$ & $\begin{array}{l}\text { National Health Service } \\
\text { Information Authority }\end{array}$ \\
\hline France & $\begin{array}{l}\text { Guide méthodologique de comptabilité } \\
\text { analytique hospitalière } \\
\text { https://solidarites- } \\
\text { sante.gouv.fr/IMG/pdf/guide_cah__bos } \\
\text { 2011- } \\
\text { 5.pdfhttp://www.sante.gouv.fr/IMG/pdf } \\
\text { /GUIDE_CAH__BOS_2011-3.pdf } \\
\text { technical package for hospital managers } \\
\text { available from: } \\
\text { https://solidarites- } \\
\text { sante.gouv.fr/professionnels/gerer-un- } \\
\text { etablissement-de-sante-medico- } \\
\text { social/performance-des-etablissements-de- } \\
\text { sante/comptabilite- } \\
\text { analytique/article/comptabilite-analytique- } \\
\text { hospitaliere }\end{array}$ & $\begin{array}{l}\text { Direction générale de } \\
\text { l'offre des soins }\end{array}$ & $\begin{array}{lr}\text { ATIH } & \text { (Agence } \\
\text { technique } & \text { sur } \\
\text { l'information } & \\
\text { hospitalière) } & \end{array}$ \\
\hline Germany & $\begin{array}{l}\text { Kalkulationshandbuch } \\
\text { https://www.g- } \\
\text { drg.de/Kalkulation2/DRG- } \\
\text { Fallpauschalen_17b_KHG/Kalkulationsh } \\
\text { andbuch }\end{array}$ & $\begin{array}{lr}\text { Institut für } & \text { das } \\
\text { Entgeltsystem } & \text { im } \\
\text { Krankenhaus (InEK) } & \end{array}$ & $\begin{array}{lr}\text { Institut für das } \\
\text { Entgeltsystem im } \\
\text { Krankenhaus (InEK) }\end{array}$ \\
\hline Ireland & $\begin{array}{l}\text { Activity Based Funding } 2019 \text { Admitted } \\
\text { Patient Price List (www.hpo.ie) }\end{array}$ & Health Pricing Office & Health Pricing Office \\
\hline Netherlands & $\begin{array}{l}\text { Kostprijsmodel zorgproducten medisch } \\
\text { specialistische zorg. Utrecht: Nederlandse } \\
\text { Zorgautoriteit. } 2012\end{array}$ & $\begin{array}{l}\text { Dutch Health care } \\
\text { Authority- Nederlandse } \\
\text { Zorgautoriteit }\end{array}$ & DBC-onderhoud \\
\hline Portugal & $\begin{array}{l}\text { Plano Oficial Contabilidade Ministério da } \\
\text { Saúde - Official Accounts Plan }\end{array}$ & Ministry of Health & $\begin{array}{l}\text { Central Administration } \\
\text { of the Health System } \\
\text { (ACSS) (under the } \\
\text { authority of the Ministry } \\
\text { of Health) }\end{array}$ \\
\hline
\end{tabular}




\begin{tabular}{|c|c|c|c|c|c|}
\hline & $\begin{array}{l}\text { To produce } \\
\text { cost reports } \\
\text { for use within } \\
\text { hospitals }\end{array}$ & $\begin{array}{l}\text { To } \\
\text { inform/calcul } \\
\text { ate national } \\
\text { DRG weights }\end{array}$ & $\begin{array}{l}\text { To } \\
\text { inform/s } \\
\text { et local } \\
\text { prices }\end{array}$ & $\begin{array}{l}\text { Benchmarking } \\
\text { with other } \\
\text { providers }\end{array}$ & Other: \\
\hline Denmark & & X & & & $\begin{array}{l}\text { Regional transfer } \begin{array}{l}\text { prices \& } \\
\text { assessing } \\
\text { costs }\end{array} \\
\text { private hospital }\end{array}$ \\
\hline England & $\mathrm{X}$ & $\mathrm{X}$ & & $\mathrm{X}$ & Development of DRG system \\
\hline France & 2 & $\mathrm{X}$ & & $\mathrm{X}$ & Development of DRG system \\
\hline Germany & $\mathrm{X}$ & $\mathrm{X}$ & $\mathrm{X}$ & $\mathrm{X}$ & Development of DRG system \\
\hline Ireland & $\mathrm{X}$ & X & & X & $\begin{array}{l}\text { Ad hoc data requests (e.g. } \\
\text { HSE/DOH, FOI) \& research }\end{array}$ \\
\hline $\begin{array}{l}\text { Netherland } \\
\mathrm{s}\end{array}$ & $\mathrm{X}$ & $\mathrm{X}$ & $\mathrm{X}$ & $\mathrm{X}$ & $\begin{array}{l}\text { Economic evaluations \& } \\
\text { academic research }\end{array}$ \\
\hline Portugal & $\mathrm{X}$ & $\mathrm{X}$ & & & $\begin{array}{l}\text { Economic evaluations \& } \\
\text { academic research }\end{array}$ \\
\hline
\end{tabular}

Table 2: Purposes of clinical costing 


\begin{tabular}{|c|c|c|c|}
\hline 80 & $\begin{array}{l}\text { Sample number of } \\
\text { hospitals (in. } \%)\end{array}$ & Total number of hospitals & Selection criteria \\
\hline Denmark & $44(100 \%)$ & 44 & $\mathrm{~N} / \mathrm{A}$ \\
\hline England & $392(100 \%)$ & 392 & $\mathrm{~N} / \mathrm{A}$ \\
\hline France & 143 in $2020^{1}(7.6 \%)$ & 1894 in $2019^{2}$ & $\begin{array}{l}\text { Acceptance of a supervisor, use of a } \\
\text { software designed for NSC, transfer of } \\
\text { data with a specific methodology }\end{array}$ \\
\hline Germany & $282(19.5 \%)$ & 1447 & $\begin{array}{l}\text { Voluntary participation; } 40 \text { hospitals } \\
\text { were sampled in } 2016 \text { based on hospital } \\
\text { ownership and DRG services, and were } \\
\text { obliged to submit cost data for five } \\
\text { years to increase data } \\
\text { representativeness }\end{array}$ \\
\hline Ireland & $39(67.5 \%)$ & 58 & $>2,000$ discharges \\
\hline Netherlands & $13-23$ & 94 & $\begin{array}{l}\text { Voluntary participation, different } \\
\text { samples per type of hospital }\end{array}$ \\
\hline Portugal & $\begin{array}{l}\text { All NHS hospitals } \\
(100 \%)\end{array}$ & ca. 60 & - \\
\hline
\end{tabular}

Table 3: Sample characteristics of providers contributing cost data for DRG weight calculation

\footnotetext{
${ }^{1}$ Agence Technique de l'Information sur l'Hospitalisation (ATIH), Echantillon ENC MCO - Campagne 2020

${ }^{2}$ Agence Technique de l'Information sur l'Hospitalisation (ATIH), Chiffres clés MCO 2019, June 2020
} 


\begin{tabular}{|l|l|}
\hline Countries & \multicolumn{1}{c|}{ Link } \\
\hline Denmark & Between accounts and costing \\
\hline England & Between high-level accounts and costing \\
\hline France & Between detailed accounts and costing \\
\hline Germany & Between detailed accounts and costing \\
\hline Ireland & Between high-level accounts and costing \\
\hline Netherlands & Between detailed accounts and costing \\
\hline Portugal & Between high-level accounts and costing \\
\hline
\end{tabular}

Table 4: Link between chart of account and costing 


\begin{tabular}{|l|c|c|c|}
\hline & \multicolumn{3}{|c|}{ Main cost objects of cost calculation } \\
\hline Countries & DRG & Specialty/Service line & Patient \\
\hline Denmark & $\mathrm{M}$ & $\mathrm{O}$ & $\mathrm{M}$ \\
\hline England & $\mathrm{M}$ & $\mathrm{O}$ & $\mathrm{O}$ \\
\hline France (1) & $\mathrm{M}$ & $\mathrm{M}$ \\
\hline Germany (1) & $\mathrm{M}$ & $\mathrm{M}$ & $\mathrm{N}$ (yes*15 pilot sites) \\
\hline Ireland & $\mathrm{M}$ & $\mathrm{M}$ & $\mathrm{M}$ \\
\hline Netherlands & $\mathrm{M}$ & $\mathrm{M}$ & $\mathrm{M} / \mathrm{O}$ \\
\hline Portugal (2) & $\mathrm{N}$ & $\mathrm{M}$ & $\mathrm{N}$ \\
\hline
\end{tabular}

Table 5: Main cost objects of calculation $(\mathrm{M}=$ mandatory, $\mathrm{O}=$ optional guidance to support, $\mathrm{N}=$ not formally supported)

(1): Information applies to hospitals that voluntarily participate in the cost information collection sample.

(2): Costs are calculated at the patient level but are not collected at this level. 
Activity-Based Costing (ABC): Activity-Based Costing (ABC) is an approach to attribute indirect costs to cost objects. It is an alternative to volume-based attribution of indirect costs to cost objects (i.e., by allocating costs across volume). ABC makes cause-and-effect relationships visible by disaggregating indirect costs into the costs of activities for which cause-and-effect cost drivers can be established. For example, the finance department's costs are indirect costs, for which no single cost driver offers a clear reflection of cause-and-effect. Activity-Based Costing would break this total cost down into resources (e.g. staff, equipment, etc.) that can be traced to activities (e.g., running the payroll, credit control) using appropriate cause-and-effect cost drivers which can be found to allocate the costs. NB: ABC can be based on top-down or a bottom-up costing (see Time-Driven ABC).

Bottom-up costing: Bottom-up costing refers to the methodological choice to aggregate up the cost of the chosen cost object from units of resource cost analyzed at a lower level of aggregation. For example, if total operating theatre costs are divided out across total patient minutes, this cost per minute can then be aggregated up to individual patients. NB: the choice of bottom-up/top-down is independent of other methodological choices such as volume/activitybased analysis of cost behaviour. In practice, pure forms of any of these choices are rare.

Cause-and-effect relationships: The essence of a costing system, whether top-down or bottom-up, activity or volume-based, is establishing cause-and-effect relationships between costs and the cost object. Cause-and-effect relationships make costs transparent and manageable.

Chart of accounts: The financial accounting system is linked to costing through the chart of accounts. This chart prescribes the accounts to be used in the book-keeping system, defining how cost information is initially recorded. The detail and structure of the accounts then influence the structure of cost centres and pools.

Cost object: A cost object is an item such as a product, service, department, doctor, patient, or group of patients for which costs are calculated.

Cost centre: A unit of an organization, for which its manager is responsible for the costs arising in that unit. In hospitals, these often correspond to clinical departments.

Cost drivers: The factors that most closely influence the costs of an activity or a certain kind of cost in relation to a cost object.

Costing method: The costing method defines how costs are calculated. The most common methods of calculating costs are: 1) the definition of the main cost objects (e.g., patient-, DRG- or specialty- level); 2) the disaggregation or aggregation of costs (i.e., top-down or bottom-up costing); and 3) the attribution of indirect costs to cost objects (i.e., volume or activity-based). Costing guidance may define different cost objects. They usually also consist of a mix of ways to attribute indirect costs to cost objects (volume and activity-based) and a mix of aggregating and disaggregating costs (top-down and bottom-up costing).

Cost pool: All service costs (including direct, indirect, and overhead costs) are grouped into cost pool groups (e.g., electricity, physicians' costs, costs of nurses, costs of medication) to enable analysis. An activity-based approach to cost pools facilitates establishing cause-and-effect relationships (see ABC).

Costing guidance: Costing guidance is used here to describe any formal support edited at the institutional level, i.e., governments, regulators, or policymakers, to support costing at the healthcare provider level. The guidance includes standards, rules, recommendations, or other formalizations of procedures. Guidance, in this sense, may be optional or mandatory.

Direct cost: In the U.K. healthcare environment, a distinction is made between direct cost, indirect cost, and overhead. In terms of cost analysis, however, the central distinction is between costs that may be related through cause-and-effect to cost objects (i.e., direct costs) and those which cannot (i.e., all other costs). Outside of the field of healthcare, the terms indirect cost and overhead are generally used synonymously.

General ledger: The system of accounting records of transactions relating to a company's assets, liabilities, owners' equity, revenue, and expenses.

Sampling: Sampling is the selection of a subset of healthcare providers to estimate the characteristics of all providers. Two advantages of sampling are that the cost is lower, and data collection is faster.

Service-line: With service line management, a hospital trust is divided into specialist clinical areas that are then managed as distinct operational units led by clinicians.

Costing for a specialty/department: Calculating costs for a specialty service. Could be based on a top-down or bottom-up methodology

Time-Driven Activity-Based Costing (TDABC): This costing method is the development of ABC. The original $\mathrm{ABC}$ was often conceived as a top-down costing approach. TDABC is the bottom-up development of $\mathrm{ABC}$. It requires 
answering the following two questions: How much does it cost to provide each process's resource capacity? How much resource capacity (time) is required to perform work for each order, product, or service?

Top-down costing: Top-down refers to the methodological choice to disaggregate the cost of the chosen cost object from costs analyzed at a higher aggregation level than the cost object. For example, total operating theatre costs might be divided out across the total number of patients. N.B. the choice of bottom-up/top-down is independent of other methodological choices such as volume/activity-based analysis of cost behaviour. In practice, pure forms of any of these choices are rare.

Traditional volume-based costing: Volume-based attribution of indirect costs to cost objects (i.e., allocating costs across volume). First, an allocation base, such as the direct costs or a profit centre's turnover, is chosen. The indirect costs are then attributed in proportion to the allocation base. To that end, the cost driver is calculated by dividing the total indirect costs for a certain cost category by the chosen allocation base. For example, the cost driver for indirect material costs could accordingly be calculated as a total indirect cost for material divided by the total direct material costs. The resulting percentage can be added to the direct material costs, e.g., costs for a hip, as indirect material costs, e.g., costs for purchasing the hip and storing the hip, at the level of a cost object.

Cost avoidability: $\mathrm{ABC}$ enables us to trace costs and to identify those costs that are avoidable. Within traditional volume-based costing, costs that are, in principle, direct are often treated as indirect, as it is less costly to capture them as indirect costs rather than tracing them to the level of the cost object. This then makes it difficult to identify costs that can be avoided.

Table 6: Cost concepts glossary 